\title{
O ENSINO DO SISTEMA DEFENSIVO INDIVIDUAL NO HANDEBOL E SUAS CONSIDERAÇÕES PARA A INICIAÇÃO ESPORTIVA
}

\author{
Tathyane Krahenbühl \\ Universidade Federal de Goiás, Goiânia, Goiás, Brasil \\ Lucas Leonardo \\ Universidade Estadual de Campinas, Campinas, São Paulo, Brasil
}

\begin{abstract}
Resumo
O ensino da marcação individual no handebol no período de iniciação à modalidade é crescente. Isto ocorre devido às adaptações das regras para as categorias de base, com o objetivo de favorecer o processo de ensino-aprendizagem-treinamento dos iniciantes. $\mathrm{O}$ embasamento para essa forma de ensinar o handebol parte da percepção dos diferentes níveis de compreensão do jogo, iniciando pela fase anárquica e passando pelas fases da descentralização e da estruturação do jogo. Assim, observamos que há diversos fundamentos defensivos que podem ser desenvolvidos pelo jogador na marcação individual e que o sistema defensivo individual pode ser estrategicamente elaborado em relação ao entendimento e ao nível de percepção dos jogadores, de acordo com as suas estratégias e especificidades.
\end{abstract}

Palavras-chave: Esportes. Ensino. Pedagogia do Esporte.

\section{Introdução}

A iniciação esportiva é um assunto constante nas discussões entre os profissionais do esporte. Na elaboração dos métodos de ensino, uma das principais preocupações é como ensinar uma modalidade esportiva sem negligenciar etapas do aprendizado e sem que ocorra a especialização precoce (FRASER-THOMAS; CÔTÉ, 2006; CÔTÉ; BAKER; ABERNETHY, 2007; CÔTÉ; LIDOR; HACKFORT, 2009), e até mesmo alterações nas regras e adaptações dos regulamentos nas competições de base (BURTON; GILLHAM; HAMMERMEISTER, 2011) são alguns dos aspectos observados atualmente, com o objetivo de favorecer o processo de ensino-aprendizagem-treinamento dos iniciantes.

Os métodos de ensino como o global funcional, os jogos condicionados ou situacionais contribuem para o desenvolvimento dos jogadores de esportes coletivos, pois baseiam o desenvolvimento técnico-tático e cognitivo a partir da própria prática do jogo, constituída no elemento central no processo de ensino-aprendizagem-treinamento (GARGANTA, 1995; GRECO, 1998; LEONARDO; SCAGLIA; REVERDITO, 2009; REVERDITO; SCAGLIA; PAES, 2009).

Os esportes coletivos apresentam elementos comuns e princípios operacionais que regem a estrutura tática do jogo. Estes príncipios são divididos em ofensivos, com ações de manutenção da posse da bola, de progressão e finalização ao alvo; e defensivos, como a proteção ao alvo, o impedimento da progressão do ataque e a retomada da posse da bola 
(BAYER, 1994). Esses elementos devem ser aprendidos logo no início do processo de aprendizagem do jogador, visando à inteligência tática e à resolução de problemas no contexto do jogo (LATISKEVITS, 1991; DAOLIO, 2002; GRECO; BENDA, 1998).

A partir desta concepção, as regras de ação, juntamente com os elementos técnicotáticos, tornam-se os principais conteúdos de aprendizagem, conforme proposto por Daolio (2002), sustentado na obra de Bayer (1994), por serem formas de ensinar conteúdos gerais e transferíveis entre diferentes esportes coletivos de invasão, além de utilizar a resolução de problemas vividos na realidade do jogo, aproximando o jogador do jogo formal, sem pular etapas no processo de ensino (GRECO, 1998; LEONARDO; SCAGLIA; REVERDITO, 2009; SCAGLIA; REVERDITO; GALATTI, 2013).

Apesar desses elementos comuns aos esportes coletivos, cada modalidade tem características específicas que tornam cada esporte único e singular. No caso do handebol, além dos princípios operacionais do jogo, a modalidade apresenta a característica de invasão ao território adversário e grande aproximação entre os jogadores (BLÁZQUEZ; HERNÁNDEZ, 1984), em que há vários momentos de contato físico direto entre os jogadores (BAYER, 1987; EHRET et. al., 2002). Além disso, o handebol é um esporte com característica dinâmica, com mudanças constantes de condições entre as equipes em relação ao ataque, à defesa e à transição, sendo que, na iniciação esportiva, faz-se necessário trabalhar aspectos cognitivos, como a tomada de decisão e a rápida resolução de problemas dentro do contexto do jogo (LATISKEVITS, 1991; MENEZES; REIS; MORATO, 2016).

Substancialmente, as possibilidades de aprendizagem da criança e do jovem obedecem a diferentes níveis de compreensão, iniciando pela fase anárquica, passando pelas fases da descentralização e da estruturação do jogo, para, somente após um longo período de aprendizagem, as características do jogo formal e mais elaborado sejam integradas (GARGANTA, 1995).

Dessa forma, há uma crescente discussão sobre os meios táticos, tanto individuais quanto grupais, bem como sistemas defensivos que devem ser ensinados na faixa etária dos iniciantes, como nas categorias mirim (11 e 12 anos de idade) e infantil ( 13 e 14 anos de idade), tornando a disputa presente na dualidade ataque-defesa do jogo uma ferramenta de ensino e adaptando o jogo possível, tornando-o mais atraente para aqueles que ainda estão em processo de aprendizagem.

Pensando nisso, algumas mudanças na forma como se ensina o handebol geram muitas discussões entre os profissionais que trabalham com a iniciação na modalidade e com as equipes de base do esporte, induzindo adaptações nos regulamentos de competições das federações estaduais, ligas e demais organizações competitivas nacionais, com o objetivo de tornar o espaço competitivo um local para o desenvolvimento desses iniciantes. Afinal, acredita-se que a participação em competições deva ser adequada ao entendimento, ao crescimento e ao desenvolvimento do indivíduo, no sentido de formação estruturada do jogador de handebol (MARQUES, 1997; GRECO; SILVA; GRECO, 2012).

Entre essas discussões e adaptações, constata-se como mais frequente no contexto do handebol brasileiro a obrigatoriedade de executar diversos tipos de defesas, como a marcação individual ou os sistemas abertos (em duas ou mais linhas) em detrimento das defesas mistas (MENEZES, 2010; MENEZES; SOUSA; BRAGA, 2011; MENEZES; REIS; NUNOMURA, 2015).

A categoria mirim, que abrange a faixa etária dos 11 aos 12 anos, faz parte de um momento de aquisição de conhecimentos básicos para as categorias futuras ao considerar as etapas de aprendizagem propostas por Garganta (1995) em função dos níveis de compreensão do jogo.

Segundo Estriga e Moreira (2013), a categoria seguinte, denominada infantil (13 a 14 anos), se caracteriza como um período de transição entre as fases de descentralização e estru- 
turação do jogo, sendo um momento de aprendizagem dependente da posse de bola e sustentada por ações individuais. Porém, nessa fase, é possível a compreensão de elementos táticos de grupo, por já ocorrer a melhor ocupação do espaço da quadra e o reconhecimento da importância dos colegas de equipe para o bom andamento do jogo, além de as funções dos alvos a atacar e defender se tornarem mais claras.

As fases de formação propostas por Ehret et. al. (2002) e Greco, Silva e Greco (2012) se assemelham em objetivos de aprendizagem, incorporando o período de formação básica, na qual a utilização da marcação individual se apresenta como o principal conteúdo defensivo a ser aprendido até os 12 anos de idade. Tanto Ehret et. al. (2002), no chamado período de treinamento de base, quanto Greco, Silva e Greco (2012), no chamado período de transição para as categorias maiores, ou seja, na categoria infantil, destacam a importância de que as condutas aprendidas durante a utilização do sistema defensivo individual sejam transferidas para a aprendizagem defensiva zonal, assim como Menezes, Sousa e Braga (2011), que apontam ser o ensino da defesa individual um caminho viável e coeso para a formação esportiva no handebol.

Assim, o ensino a partir do sistema defensivo individual é orientado pela ideia de que há simplificação do entendimento do jogo. De acordo com Menezes, Reis e Filho (2015, p.263):

A abordagem dos conteúdos ao longo do processo de formação do jogador de handebol deve ser dada a partir dos elementos mais gerais aos mais específicos, culminando na especialização do jogador após um bom domínio das habilidades básicas em diversos postos específicos.

Entretanto, apesar de o ensino da marcação individual ser considerado importante, pois está relacionado com o entendimento da lógica do jogo nas faixas etárias das categorias mirim e infantil, e de sua importância na formação do jogador para o correto trabalho defensivo (FERNÁNDEZ et. al., 2012a), ainda há divergências nas diversas formas táticas no ensino dessa defesa.

O objetivo do presente estudo consiste em apresentar os conceitos referentes às ações da marcação e do sistema defensivo individual presentes na literatura, junto com suas diversas formas de atuação na fase de iniciação, e, a partir dessa reflexão, elaborar uma proposta conceitual e metodológica para o ensino desse sistema defensivo na iniciação esportiva do handebol.

\section{Os princípios básicos do jogador defensor - elementos técnicos e táticos individuais ne- cessários para o jogo defensivo individual}

Defender significa impedir, de forma coerente ao jogo, que o atacante consiga o êxito no seu objetivo, ou seja, impedir que o ataque consiga finalizar e marcar o ponto. Para isso, os defensores devem executar ações técnicas e táticas, individual ou coletivamente, com a finalidade de criar situações de vantagem defensiva e, assim, proteger a sua meta (ANTÓN et. al., 2000; MENEZES, REIS; FILHO, 2015). Segundo Bayer (1994), o conceito de defesa em jogos de invasão como o handebol abrange os momentos de recuperação da bola (interceptar, antecipar, dissuadir, flutuar, pressionar), de evitar a progressão à meta e de proteger a meta (bloqueio de lançamento).

Marcação significa a ação, o comportamento, o desempenho individual diante do sistema defensivo adotado pela equipe, resultante da ação técnica, tática e psicológica. Envolve ações como observar, vigiar, aproximar, combater, dificultar as ações ofensivas do adversário, baseadas na antecipação do espaço com o objetivo de evitar a progressão do atacante e a recuperação da posse de bola (SIMÕES, 2008). 
A marcação individual é caracterizada como a disputa entre um defensor e um atacante específico e determinado, impedindo o recebimento da bola ou a progressão e finalização ao gol daquele adversário e condicionando o êxito ou o fracasso individual como sendo de toda a equipe. De acordo com Martini (1980, p. 159), "todo o jogo de equipe se resolve, por assim dizer, em seis duelos".

O desenvolvimento da capacidade defensiva individual é de grande importância, principalmente nos períodos de maior aquisição de habilidades motoras fundamentais à prática esportiva e necessárias para as ações técnicas e táticas do jogo em todos os sistemas defensivos adotados (EHRET et. al., 2002). De acordo com Menezes e Reis (2014), até mesmo os treinadores mais experientes enxergam que as principais ações defensivas são as situações de $1 \times 1$, fundamentais para manter o controle do adversário com ou sem bola, mesmo quando adotados sistemas defensivos tradicionais.

Simões (2008) aponta que a ação individual do defensor, dentro de um sistema defensivo zonal, é essencial para evitar os deslocamentos e arremessos do ataque e fundamental para organizar as ações defensivas em equipe, pois jogadores que sabem bem as ações defensivas individuais poderão executá-las em qualquer sistema defensivo (LATISKEVITS, 1991).

A execução eficaz de variadas ações técnicas e táticas individuais faz-se necessária para garantir o dinamismo do sistema defensivo (EHRET et. al., 2002). Os métodos de ensino participativos, nos quais as atividades e as situações propostas aos jogadores provocam a busca de soluções para determinadas situações do jogo, devem garantir esse dinamismo (MENEZES; REIS; FILHO, 2015).

Assim, algumas ações devem ser compreendidas pelo jogador defensor, tal como o seu posicionamento dentro de quadra (GRECO; SILVA; GRECO, 2012), que deve sempre permanecer entre o seu adversário e a baliza e a observação da movimentação do adversário deve ser constante, a fim de se estar preparado para reagir em todas as situações e observar as ações do jogo como um todo, para tomadas de decisão antecipadas coerentemente mais inteligentes e concretas (MARTINI, 1980; LATISKEVITS, 1991; SIMÕES, 2008; FERNÁNDEZ et. al., 2012a).

As principais tarefas do jogador, no sistema de marcação individual, consistem em diminuir o espaço do adversário para impedi-lo de progredir e ir para o espaço livre, obrigando o jogador atacante a deslocar-se para espaços desfavoráveis para o ataque e impedindo-o também de receber a bola ou realizar o arremesso ao gol (MARTINI, 1980; EHRET et. al., 2002).

Ações de pressão contra o adversário, que consistem na aproximação em momentos específicos, provocando atitudes precipitadas e erros de fundamentos do atacante, tais como a dissuasão, que consiste na aproximação do defensor em relação ao seu marcador direto quando está sem a posse da bola e é um possível receptor (BAYER, 1987), e a flutuação, que é a aproximação do defensor em relação ao seu oponente direto quando este se encontra com a posse da bola (FERNÁNDEZ et. al., 2012b), devem fazer parte do repertório de habilidades individuais do jogador defensor.

Além disso, há outros aspectos relevantes, tais como aprender a defender o braço de arremesso do atacante, concentrar a atenção sobre a bola e correta análise sobre o tempo de reação do adversário (LATISKEVITS, 1991; FERNÁNDEZ et. al., 2012b).

Os meios táticos individuais utilizados pelo jogador defensor no jogo de handebol consistem na marcação, que pode ser realizada à distância ou com a proximidade do jogador com ou sem a bola; no bloqueio do arremesso, com o objetivo de "cortar" a trajetória da bola em direção ao gol, e na interceptação do passe e na retirada da bola no drible, com a finalidade de retomada da posse de bola (EHRET et. al., 2002; FERNÁNDEZ et. al., 2012a).

Resumidamente, o jogador defensor individualmente deve: 
- posicionar-se: sempre entre o seu oponente direto e a baliza, com o objetivo de impedir a sua progressão ao alvo e diminuir o espaço de atuação desse atacante;

- interceptar a bola: realizar a interceptação do passe direcionado ao atacante, e ter atenção ao braço de arremesso e de drible do jogador para ações de retomada da posse de bola;

- pressionar: a marcação "homem a homem" visa à aproximação do defensor do atacante, em situações de flutuação e dissuasão;

- estudar as ações do adversário, tais como em quais situações (posição, apoio, sustentado) realiza os melhores arremessos, que situações o atacante provoca para distrair o defensor (deslocamentos, fintas, desmarques);

- ter capacidade de neutralizar o atacante: para que não possa marcar gol e, se possível, não receber a bola, se necessário utilizando o contato físico direto;

- estar atento ao local onde está a bola e o adversário, pois, quanto mais perto o atacante estiver da baliza ou da bola, mais próximo e mais contato físico terá com o adversário;

- ajudar os companheiros de equipe, caso forem vencidos pelo adversário.

\section{Os princípios básicos da marcação individual enquanto sistema defensivo}

A colaboração de todos os defensores faz-se necessária para a formação da tática defensiva, tendo êxito frente às ações ofensivas do ataque, e a ação individual é fundamental para a execução tanto da tática individual quanto a de grupo (MARTINI, 1980; SIMÕES, 2008).

A marcação individual também pode ser trabalhada como um sistema defensivo, pois, apesar de estar pautada em ações de $1 \mathrm{x} 1$ (um jogador defensor contra um jogador do ataque), ela pode ser estrategicamente organizada de diferentes formas, a fim de que a equipe defensora consiga pressionar o ataque adversário. Assim, de acordo com Fernández et. al. (2012b, p. 205-206):

É um sistema no qual cada defensor se encarrega de um atacante e não de uma zona concreta, como ocorre nos demais sistemas tratados. A sua finalidade pode-se resumir nos seguintes pontos: Dificultar a criação e o ritmo do ataque, levar o ataque para zonas não perigosas, recuperar a posse de bola ou a finalização rápida do ataque em zonas desvantajosas.

Há diferentes formas estratégicas da marcação individual, que podem ser associadas à relação estabelecida entre o atacante e o defensor e também em relação à ocupação do terreno de jogo (MARTINI, 1980; EHRET et. al., 2002). Com o objetivo de que o oponente direto possa ser controlado pelo defensor, diferentes distâncias e posicionamentos entre o defensor e seu atacante direto podem ser estabelecidos (Figura 1). Assim, os principais tipos de marcação propostos são:

a) marcação por aproximação ou de perto: significa que o defensor estará bem próximo ao atacante direto. Pressupõe contato físico e pode ser usada principalmente quando o jogador está próximo aos 9 metros e também em posse de bola (Figura 1a);

b) marcação por vigilância: o defensor deve observar o adversário e estar em prontidão para intervir quando necessário. Pode ser utilizada quando o adversário estiver com ou sem a posse de bola e também quando oferecer menor perigo (Figura 1b);

c) marcação por posicionamento: o defensor se coloca entre o atacante com posse de bola e o seu oponente direto. É utilizada principalmente para a interceptação do passe e nas posições do pivô e dos extremos (Figura 1c). 


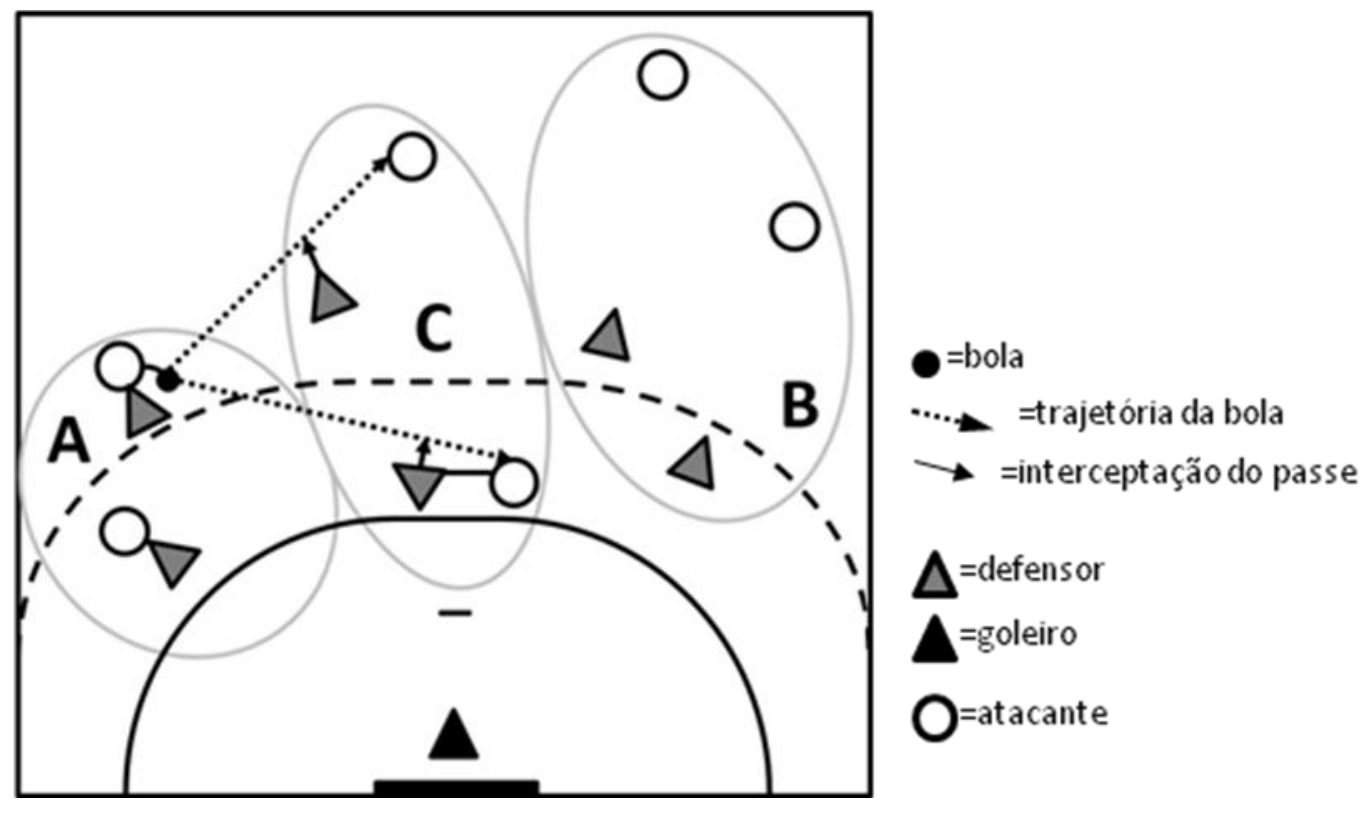

Figura 1. Defesa individual em relação à distância entre o defensor e seu atacante direto. Fonte: Elaborado pelos próprios autores, 2017

A organização do sistema individual também é realizada em relação ao espaço de jogo, que pode ser dividido em defesa de quadra inteira, na metade da quadra, em linha de 9 metros ou por aglomeração, conforme a Figura 2 (EHRET et. al., 2002; FERNÁNDEZ et. al., 2012a). São propostas nas seguintes formas:

a) na marcação quadra inteira, em que a atenção do defensor está estritamente relacionada ao seu oponente direto e a bola, com o acompanhamento do seu atacante em qualquer local da quadra (Figura 2a);

b) na marcação em metade da quadra, em que a aproximação do defensor em relação ao seu oponente direto ocorre com a aproximação do atacante em relação à baliza, ou seja, assim que o atacante passa da linha central da quadra, a marcação irá se aproximar até que ocorra o contato físico entre o defensor e seu oponente direto em torno dos 9 metros (Figura 2b);

c) segundo Fernández et. al. (2012a), a marcação por aglomeração acontece próxima à região dos 10-11 metros da quadra de defesa. Nessa marcação, há mais proximidade entre o jogador com a bola ou mais perigoso e a marcação por vigilância, quando a bola está mais afastada. Esse tipo de marcação garante situações coletivas, como a ajuda entre os defensores, e pode ser realizada em duas formas de emparelhamento: a nominal, em que cada defensor tem um oponente direto e específico na outra equipe, e a zonal, na qual a responsabilidade está no posto ocupado pelo jogador do ataque (Figura 2c). 


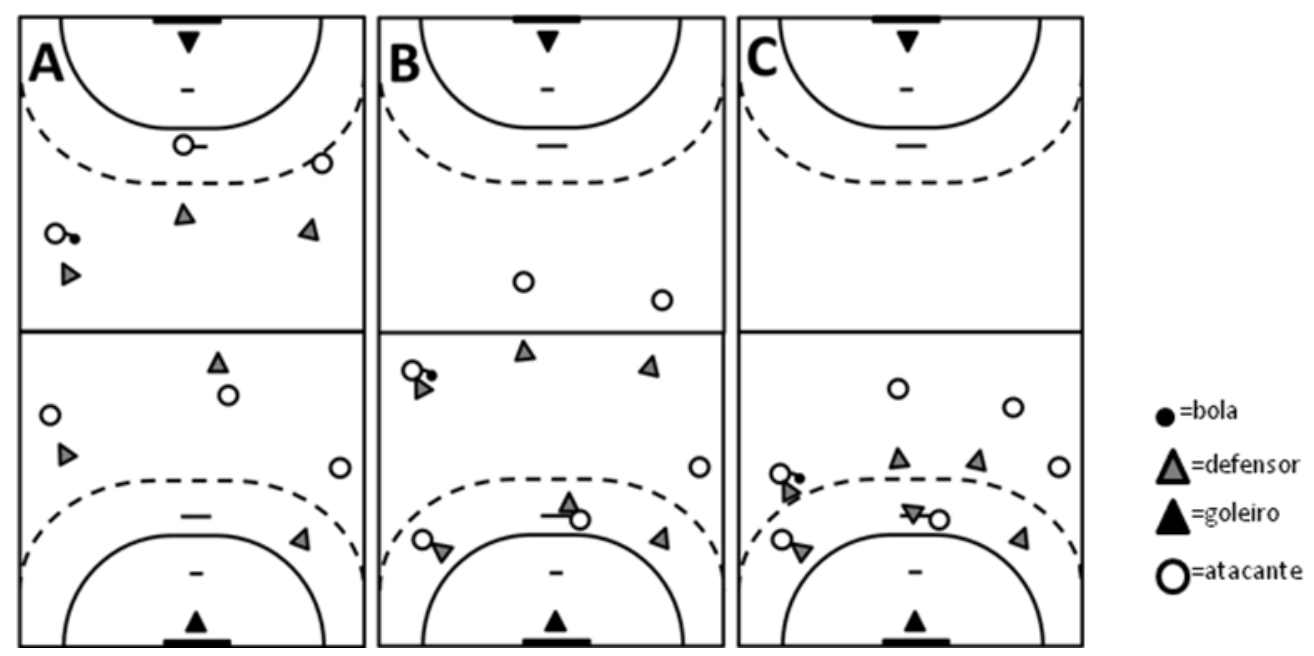

Figura 2. Defesa individual em relação à ocupação do terreno de jogo. Fonte: Elaborado pelos próprios autores, 2017

As diversas formas estratégicas de se organizar o sistema individual partem tanto das características da idade e de nível de aperfeiçoamento dos jogadores quanto do entendimento do professor sobre qual estratégia será melhor utilizada pela sua equipe nos diversos momentos do jogo. Assim, o profissional poderá partir da marcação individual simples, na qual o jogador acompanha seu oponente direto em qualquer lugar da quadra, limitando as ações coletivas no sistema até chegar à marcação por aglomeração, quando os jogadores poderão, mesmo que na marcação nominal, executar ações defensivas de grupo, tais como trocas de atacantes entre dois defensores, e na ajuda, que consiste em dois defensores para um mesmo atacante, quando necessário.

\section{Principais características da defesa individual no jogo do handebol}

O ensino da marcação individual é uma importante ferramenta pedagógica utilizada na iniciação ao handebol, em razão de suas características de dinamismo e grande exigência de participação dos jogadores nas diversas técnicas e táticas individuais defensivas, necessárias para o bom desenvolvimento motor e cognitivo que será utilizado em todos os sistemas defensivos.

Entretanto, a marcação individual pode ser utilizada em qualquer faixa etária. A escolha para sua utilização é bastante variada, mas, principalmente, quando se necessita da rápida recuperação da posse de bola, quando se quer pressionar o ataque adversário, em situações em que a equipe defensora precisa aumentar o número de pontos no placar rapidamente, como no final de jogo, ou mesmo quando há superioridade numérica da defesa, em situações de exclusão de jogadores da equipe adversária (MARTINI, 1980; EHRET et. al., 2002; FERNÁNDEZ et. al., 2012b).

Entretanto, existem algumas vantagens e desvantagens em relação ao seu uso durante partidas oficiais de handebol. Segundo Martini (1980), as vantagens são que a equipe defensora poderá retomar a bola rapidamente e em maior quantidade de vezes, principalmente se o adversário for mais fraco, pois irá pressioná-lo e consequentemente causar ações de perda da bola (passe precipitado e inexato, erros técnicos como passadas a mais ou duplos dribles). Além do mais, o jogo se tornará ainda mais rápido, fazendo com que os árbitros tenham que se atentar ao jogo passivo com mais frequência. As desvantagens são que há um grande desgaste físico, se houver atacantes mais preparados poderão vencer os defensores com facilidade, e este tipo de defesa quase não permite ajudas entre os defensores. 
Já para Latiskevits (1991), a utilização da defesa individual em quadra inteira só deve ser usada em algumas situações específicas, tais como quando a equipe, no final da partida, estiver perdendo de poucos gols e precisar reter rapidamente a bola e quando jogar contra uma equipe menos veloz ou com preparação física inferior.

Entretanto, o uso da defesa individual faz-se mais intenso nas categorias menores, principalmente entre os iniciantes, pois irá desenvolver as habilidades técnicas e táticas dos jogadores. Além disso, é um tipo de defesa fundamentalmente mais ofensivo (EHRET et. al., 2002), em que se espera que o defensor tenha pró-atividade nas decisões e resoluções dentro das relações de jogo entre ataque e defesa.

\section{Princípios para a ação pedagógica no uso do sistema defensivo individual nas categorias de base no handebol}

Vimos que várias formas de ensino são destacadas para o aprendizado e o aperfeiçoamento esportivo. A parte relevante desse processo está pautada no comportamento técnico e tático dos jogadores, que devem ser aptos a resolver as situações-problema encontradas nos diversos momentos do jogo. Por isso, os jogadores de handebol devem ser estimulados por métodos baseados no ensino dos Jogos Esportivos Coletivos, tais como o global-funcional e o situacional (GRECO, 1998; MENEZES; REIS, 2014), que estimulam as decisões dos jogadores a partir das relações estabelecidas entre os jogadores da sua própria equipe, adversários, bola e alvos (MENEZES; REIS, 2017).

A intencionalidade das ações é determinante para a compreensão e o desenvolvimento do jogo. No processo de ensino-aprendizagem, o jogador deve, além do aprendizado da execução dos fundamentos técnicos, entender a lógica do jogo, juntamente com seu dinamismo e suas tomadas de decisão (GRECO, 1998; GRECO; SILVA; GRECO, 2012).

Nas fases iniciais de formação, o princípio fundamental é o de jogar para aprender (LEONARDO; SCAGLIA; REVERDITO, 2009). No handebol, é possível utilizar as mais variadas formas de marcação individual, com trabalhos em grupos menores (1x1, 2x2 e 3x3) e a luta pela posse de bola com menor número de faltas defensivas, seguida da fase de transição, na qual se deve desenvolver a capacidade tática individual defensiva aliada às trocas de marcação, seguimento e deslizamento (EHRET, et. al., 2002; GRECO; SILVA; GRECO, 2012).

Assim, na categoria mirim, faz-se necessário o ensino utilizando uma grande quantidade de jogos e brincadeiras, em que os jogadores sejam instigados a todo o momento a fazer a retomada da bola, seja por meio da interceptação do passe, seja mesmo pela "roubada" de bola durante a execução do drible. As ações estão mais centradas no jogador e na bola, portanto, numa marcação pautada na proximidade com o jogador e na vigilância.

Além disso, a utilização da marcação individual também proporcionará ao atacante mais ações ofensivas individualizadas, tais como uma maior movimentação dentro de quadra e a utilização, com maior frequência e variedade, das fintas e dos desmarques.

Dessa forma, a utilização da marcação individual nessa categoria deve ser orientada para a aquisição de habilidades individuais e para o entendimento do jogo de maneira simplificada, em que o jogador terá estímulos pautados nas ações de 1x1 e consequentemente 2x2, ainda com pouca utilização de ajudas e trocas defensivas entre os seus companheiros de equipe.

Os espaços podem ser variados, orientados de acordo com as habilidades específicas que devem ser aprendidas. Ou seja, os espaços menores auxiliam nas ações de retomada de bola (interceptação), atuação sobre pressão (dissuasão e flutuação), controle físico e ocupação de espaços para impedir o avanço do adversário, enquanto a ampliação do espaço favorecerá o aprendizado de deslocamentos, seguimento e a atuação por vigilância. 
A utilização da marcação individual como forma de ensino está baseada na ideia de que, quanto mais estimuladas as ações individuais, melhores serão as qualidades técnicas e táticas do jogador, uma vez que, quanto maiores e mais variadas as habilidades técnicas do jogador de handebol, mais jogadas táticas ele será capaz de executar e maior será sua capacidade de criar situações de jogo, pois será estimulado nas ações de atacante $\mathrm{x}$ defensor a decidir por conta própria diferentes ações táticas (LATISKEVITS, 1991), sendo o ponto principal do treinamento de base (EHRET et. al., 2002).

Na categoria infantil, há uma fase de transição do jogo anárquico para o jogo mais organizado (GARGANTA, 1995; EHRET et. al., 2002, GRECO; SILVA; GRECO, 2012). Dessa forma, a utilização de um sistema individualizado e mais pautado no posicionamento dentro da quadra, como um sistema por aglomeração em que há características de marcação individual por aproximação parece ser mais adequado para a fase de aprendizagem. O defensor estará mais preocupado com a posição pela qual deve se responsabilizar dentro de quadra, ou seja, sua atenção não estará voltada para apenas um jogador em especial, mas em todo e qualquer jogador que venha ocupar a sua área defensiva. Com isso, vai promover mais ações de trocas defensivas, coberturas e ajudas, proporcionando uma transição entre o sistema individual e os sistemas defensivos zonais.

Nessa fase, os jogos com número reduzido de jogadores, tais como $2 \times 2$ e $3 \times 3$, devem ser priorizados, uma vez que permitirão que os elementos técnicos e táticos sejam realizados com maior frequência. A amplitude espacial nesses jogos determinará o nível de dificuldade a ser estabelecido para os defensores, ou seja, espaços menores vão permitir ações mais precisas, enquanto amplitudes maiores favorecerão as ações dos atacantes.

Assim, será estimulada a capacidade de antecipação dos jogadores (LATISKEVITS, 1991) e se fará a progressão do jogo descentralizado para o mais complexo. Neste momento, o jogador não precisa se preocupar apenas com o seu oponente direto, mas com uma situação mais variada de situações ofensivas, como tabelas e cruzamentos, sendo necessário que o defensor entenda as ações de deslocamento do atacante para saber qual decisão tomar, se acompanha o seu direto ou se troca com o seu companheiro.

As ações de grupo defensivas vão ocorrer com maior frequência devido à proximidade entre os jogadores defensores, estimulando as ações de trocas defensivas, dobras, ajudas, deslizamentos e contrabloqueios.

Nas próximas categorias de competição (cadete e juvenil), esses conceitos, princípios e ações da marcação, juntamente com os fundamentos técnicos e táticos individuais, devem estar amplamente reconhecidos e incorporados no entendimento do jogador de handebol, possibilitando o seu aperfeiçoamento e o seu desenvolvimento em sistemas mais complexos de jogo e tornando-o um defensor mais ativo.

\section{Considerações finais}

A marcação individual é bastante utilizada em regulamentos de competições oficiais em categorias de base do handebol em várias partes do país. Com isso, entender como organizar um sistema defensivo individual é bastante importante para o auxílio dos profissionais que estão trabalhando com as faixas etárias das categorias mirim e infantil.

Diversas formas de organização desse sistema foram apresentadas, tais como a marcação individual quadra inteira, meia quadra, por aproximação, por vigilância, por aglomeração, com a finalidade de distinguir e orientar as fases de aprendizado, com as dificuldades de cada organização defensiva, em relação aos espaços e também ao número de jogadores $(1 \times 1,2 \times 2$, $3 \times 3)$. Além disso, foi possível observar que o aprendizado dos fundamentos defensivos individuais é importante na formação dos jogadores, uma vez que as ações individuais são neces- 
sárias para o êxito na execução de todos os sistemas defensivos, seja no individual, seja nas várias defesas zonais ou mistas.

Por isso, uma proposta pedagógica para o ensino do handebol baseada na marcação individual pautada nas categorias de base e no nível de aprendizado foi apresentada, sugerindo qual tipo de sistema individual utilizar para cada nível, utilizando jogos com número de jogadores e espaços reduzidos, a fim de orientar os profissionais do esporte a entenderem as diversas variações que podem ser utilizadas de acordo com o contexto em que a sua equipe está inserida.

\title{
THE TEACHING OF THE INDIVIDUAL DEFENSE IN HANDBALL AND ITS CON- SIDERATIONS FOR SPORTS INITIATION
}

\begin{abstract}
The teaching of individual defense in handball is increasing in the initiation of the modality, due to the adaptations of the rules for the basic categories, with the aim of favoring the teaching-learning-training process of beginners. The basis for this way of teaching handball starts from the perception of different levels of understanding of the game, starting with the anarchic phase, through the phases of decentralization and structuring of the game. Thus, we observe that there are several defensive fundamentals that can be developed by the player in the individual defense, and that the individual defensive system can be strategically elaborated in relation to the players' understanding and level of perception, and according to the strategies and specificities of this system.
\end{abstract}

Key-words: Sports. Teaching. Sport Pedagogy.

\section{LA ENSEÑANZA DEL SISTEMA DE DEFENSA INDIVIDUAL EN EL BALON- MANO Y SUS CONSIDERACIONES PARA LA INICIACIÓN DEPORTIVA}

\begin{abstract}
Resumen
La enseñanza de la marcación individual en el balonmano está creciendo en el processo de enseñanza en la iniciación de la modalidad apoyado em los ajustes de las reglas para las categorías de base, con el fin de promover el proceso de enseñanza-aprendizaje-entrenamiento de los principiantes. La base de esta forma de enseñanza de balonmano parte de la percepción de los diferentes niveles de comprensión del juego, comenzando con la etapa anárquica, a través de las fases de la descentralización y la organización del juego. Así, se observa que hay varios fundamentos defensivos que pueden ser desarrollados por el jugador en la marcación individual, y que el sistema de defensa individual se puede desarrollar estratégicamente en relación con la comprensión y el nivel de conciencia de los jugadores, de acuerdo con las estrategias y las características específicas de este sistema.
\end{abstract}

Palabras-clabe: Deportes. Enseñanza. La Pedagogía del Deporte.

\section{Referências}

ANTÓN, J. L. et. al. Balonmano: alternativas y factores para la mejora del aprendizaje. Madrid: Gymnos Editorial, 2000.

BAYER, C. Handball: la formation du joueur. 2.ed. Paris: Vigot, 1987. 
O ensino dos desportos colectivos. Lisboa: Dinalivros, 1994.

BLÁZQUEZ, D; HERNÁNDEZ, J. Clasificación o taxonomías deportivas. 1984. Monografia (Educação Física )- Institut Nacional d'Educació Física de Catalunya (INEF), Barcelona, 1984.

BURTON, D.; GILLHAM, A. D.; HAMMERMEISTER, J. Competitive engineering: Structural climate modifications to enhance youth athletes' competitive experience. International Journal of Sports Science and Coaching, v. 6, n. 2, p. 201-217, 2011.

CÔTÉ, J.; BAKER, J.; ABERNETHY, B. Practice and play in the development of sport expertise. In: TENENBAUM, G.; EKLUND, R. (Ed.). Handbook of sport psychology. Hoboken, NJ: Wiley, 2007. v. 3, p. 184-202.

CÔTÉ, J; LIDOR, R; HACKFORT, D. ISSP position stand: to sample or to specialize? Seven postulates about youth sport activities that lead to continued participation and elite performance. International Journal Sport Exercise Psychological, v.7, p. 7-17, 2009.

DAOLIO, J. Jogos esportivos coletivos: dos princípios operacionais aos gestos técnicos modelo pendular a partir das ideias de Claude Bayer. Revista Brasileira de Ciência e Movimento, Brasília, v. 10, n. 4, p. 99-103, 2002.

EHRET, A. et al. Manual de handebol. Treinamento de base para crianças e adolescentes. São Paulo: Phorte, 2002.

ESTRIGA, L.; MOREIRA, I. Proposta metodológica de ensino do handebol. In: TAVARES, Fernando (Ed.). Jogos desportivos coletivos: ensinar a jogar. Porto: FADEUP, 2013. p. 123164.

FERNÁNDEZ, J.J. et al. Fundamentos técnicos-táticos individuais na defesa. In: GRECO, P.J.; ROMERO-FERNÁNDEZ, J.J. (Org.). Manual do handebol: da iniciação ao alto nível. São Paulo: Phorte, 2012a. p.137-144.

FERNÁNDEZ, J.J. et al. Sistemas de jogo na defesa. In: GRECO, P.J.; ROMEROFERNÁNDEZ, J. J. (Org.). Manual do handebol: da iniciação ao alto nível. São Paulo: Phorte, 2012b. p.201-226.

FRASER-THOMAS, J.; CÔTÉ, J. Youth sports: implementing findings and moving forward with research. Athletic Insight, v.8, p.12-27, 2006.

GARGANTA, J. Para uma teoria dos jogos desportivos colectivos: In: GRAÇA, A; OLIVEIRA, J. (Org.). O ensino dos jogos desportivos. Porto: CEJD/FCDEF-UP, 1995, p.11-25.

GRECO, P. J. Iniciação esportiva universal 2: metodologia da iniciação na escola e no clube. Belo Horizonte: Ed. UFMG, 1998.

GRECO, P. J.; BENDA, R. N. Iniciação esportiva universal: da aprendizagem motora ao treinamento técnico. Belo Horizonte: Ed. UFMG, 1998. 
GRECO, P.J.; SILVA, S.S.; GRECO, F.L. O sistema de formação e treinamento esportivo no handebol brasileiro (SFTE-HB). In: GRECO, PJ; ROMERO-FERNÁNDEZ J.J. (Org). Manual do handebol: da iniciação ao alto nível. São Paulo: Phorte, 2012. p.235-250.

LEONARDO, L.; SCAGLIA, A. J.; REVERDITO, R. S. O ensino dos esportes coletivos: metodologia pautada na família dos jogos. Motriz, Rio Claro, v.15, n.2, p. 236-246, 2009.

LATISKEVITS, LA. Balonmano. Barcelona: Paidotribo, 1991.

MARTINI, K. O andebol. Técnica, tática, metodologia. Portugal: Publicações EuropaAmérica, 1980. (Coleção Desporto).

MARQUES, A. A preparação desportiva de crianças e jovens: o sistema de competições. In: GUEDES, O.C. (Org.) Atividade física: uma abordagem multidimensional. João Pessoa: Ideia, 1997. p. 157-169.

MENEZES, R. P. O ensino dos sistemas defensivos do handebol: considerações metodológicas acerca da categoria cadete. Pensar a Prática, Goiânia, v. 13, n. 1, p.1-16, 2010.

MENEZES, R. P.; SOUSA, M. S.S.; BRAGA, J. W. C. Processo de ensino-aprendizagemtreinamento de handebol para a categoria mirim em instituições não-formais de ensino: concepções e metodologias. Conexões, Campinas, v. 9, n. 2, 2011.

MENEZES, R.P.; REIS, H.H.B. Relação entre eficácia defensiva e elementos técnicos-táticos do handebol a partir dos discursos de treinadores experientes. Revista de Educação Física/UEM, Maringá, n. 4, p. 513-526, 2014.

MENEZES, R.P.; REIS, H.H.B.; FILHO, H.T. Ensino-aprendizagem-treinamento dos elementos técnico-táticos defensivos individuais do handebol nas categorias infantil, cadete e juvenil. Movimento, Porto Alegre, v. 21, n. 1, p. 261-273, 2015.

MENEZES, R. P.; MARQUES, R. F. R.; NUNOMURA, M. O ensino do handebol na categoria infantil a partir dos discursos de treinadores experientes. Movimento, Porto Alegre, v. 21 , n. 2, p. $463,2015$.

MENEZES, R. P.; REIS, H. H. B.; MORATO, M. P. O handebol, seu cenário imprevisível e os métodos de ensino-aprendizagem-treinamento. Revista de Ciências del Deporte, v. 12, n. 3, p. 165-176, 2016.

MENEZES, R.P.; REIS H.H.B. O jogo defensivo diante de diferentes sistemas ofensivos no handebol: análise do cenário técnico-tático e reflexões sobre o ensino. Revista Brasileira de Ciências do Esporte, v.39, n.2, p.168-175, 2017. Disponível em: < http://dx.doi.org/10.1016/j.rbce.2017.02.003>. Acesso em: 25 abr. 2017.

REVERDITO, R.S.; SCAGLIA, A.J.; PAES, R.R. Pedagogia do esporte: panorama e análise conceitual das principais abordagens. Motriz, Rio Claro, v. 15, n. 3, p. 600-610, 2009.

SCAGLIA, A. J.; REVERDITO, R. S.; GALATTI, L. R. Ambiente de jogo e ambiente de aprendizagem no processo de ensino dos jogos esportivos coletivos: desafios no ensino e 
aprendizagem dos jogos esportivos coletivos. Jogos desportivos: formação e investigação. Florianópolis: UDESC, 2013. p. 133-170.

SIMÕES, A.C. Handebol defensivo: conceitos técnicos e táticos. 2. ed. São Paulo: Phorte, 2008.

Recebido em: 03/05/2017

Revisado em: 10/07/2017

Aprovado em: 08/08/2017

Endereço para correspondência:

tathykrahenbuhl@ufg.br

Tathyane Krahenbühl

Universidade Federal de Goiás, Faculdade de Educação Física e Dança

Campus Samambaia

Avenida Esperança, s/n

Itatiaia

74690-900 - Goiânia, GO - Brasil 